\title{
INTEGRATION OF A MATHEMATICAL EXERGOECONOMIC OPTIMIZATION PROCEDURE WITH A PROCESS SIMULATOR: APPLICATION TO THE CGAM SYSTEM
}

\author{
L. S. R. Vieira ${ }^{a}$, \\ J. L. M. Donatellib, \\ and M. E. C. Cruz \\ ${ }^{a}$ CEPEL - Depto. de Tecnologias Especiais \\ CP. 68007, Rio de Janeiro, RJ, Brasil \\ 1srv@cepel.br

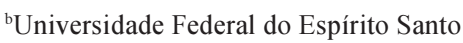 \\ Departamento de Engenharia Mecânica \\ CP. 019011, Vitória, ES, Brasil \\ joaoluiz@npd.ufes.br \\ ${ }^{c}$ Universidade Federal do Rio de Janeiro \\ Departamento de Engenharia Mecânica \\ CP. 68503, Rio de Janeiro, RJ, Brasil \\ manuel@mecanica.coppe.ufrj.br
}

\section{ABSTRACT}

In the present work a recent development and implementation of an integrated approach for mathematical exergoeconomic optimization of thermal systems is described. The proposed integrated approach is designed to exploit the computational power of a professional process simulator, so that the optimization procedure may disregard the variables associated with the thermodynamic balance equations, and thus deal with the decision variables only. To demonstrate its capabilities, the integrated approach is here applied to the CGAM system. Complete simulation of the CGAM system requires more than 200 variables. In a conventional mathematical optimization procedure, all variables must be handled simultaneously. In the proposed integrated exergoeconomic optimization approach, only 5 decision variables are manipulated by the optimization kernel, while the remaining variables are managed by the simulator. Because the thermodynamic balance equations are decoupled from the optimization problem, the proposed approach is computationally efficient, and can therefore be applied to optimize complex thermal systems.

Keywords: Mathematical optimization, exergoeconomic optimization, thermal systems, process simulator, exergy, CGAM

\section{NOMENCLATURE}

$A C$ air compressor

$B_{k} \quad$ parameter in Eqs. (9), (10) for $\mathrm{k}^{\text {th }}$ component

$B_{k l} \quad$ parameter in Eq. (10) for $\mathrm{k}^{\text {th }}$ component

$\mathrm{B}_{\mathrm{k} 2}$ parameter in Eq. (10) for $\mathrm{k}^{\text {th }}$ component

c specific exergetic cost

$\dot{C} \quad$ exergetic cost flow rate

Comb combustor

Comp component

$C R F$ capital recovery factor

$\dot{E} \quad$ exergy flow rate

GT gas turbine

$H R S G$ heat recovery steam generator

$i \quad$ interest rate

$\ell \quad$ useful system life

$\dot{m} \quad$ mass flow rate

$m_{k} \quad$ exponent in Eqs. (9), (10) for $\mathrm{k}^{\text {th }}$ component

$n \quad$ number of decision variables

$n_{k} \quad$ exponent in Eqs. (9), (10) for $\mathrm{k}^{\text {th }}$ component

$N_{C} \quad$ number of calls to the simulator

$N K \quad$ number of system components

$O F$ objective function for the CGAM system

$P E C$ purchased-equipment cost

Pre preheater
$T \quad$ temperature

TCI total capital investment

$\vec{V} \quad$ vertex of a Nelder \& Mead polyhedron

$X \quad$ decision variable

$\dot{Z} \quad$ cost rate given by Eq. (7)

\section{Greek symbols}

$\beta \quad$ multiplying factor for purchasedequipment cost

$\delta \quad$ relative difference given by Eq. (12)

$\varepsilon \quad$ exergetic efficiency

$\gamma \quad$ maintenance factor

$\eta \quad$ relative difference given by Eq. (13)

$\bar{\mu} \quad$ average value of $\mu$

$\tau \quad$ yearly plant operating hours

\section{Subscripts}

$b$ best

D exergy destruction

$f$ final

$F \quad$ fuel

$i \quad \mathrm{i}^{\text {th }}$ decision variable, $\mathrm{i}^{\text {th }}$ flow rate, initial

$k \quad \mathrm{k}^{\text {th }}$ system component

low lower limiting value 
$P \quad$ product

total total

up upper limiting value

\section{INTRODUCTION}

Nowadays, efficient utilization of natural energy resources - perhaps more appropriately, exergy resources - is mandatory for a healthy economy, which explains the recent increase in the development of techniques for energy systems optimization worldwide. Besides the need for efficiency, there is also a strong demand for reducing harm to the environment and for achieving sustainable development.

Recently, Rosen and Dincer $(2001 ; 2003)$ have proposed the application of the exergy concept as a basis to solve modern energy and environmental problems and to help achieve sustainable development. In this context, the exergoeconomics techniques can address environmental issues, reveal the cost formation process of system products, and aid system optimization. A comprehensive review of relevant publications between the 70's and 90's regarding exergy and exergoeconomic analysis is presented by Tsatsaronis (1993); a more recent survey on this field can be found in Donatelli (2002) and Vieira (2003). In Brazil, exergoeconomics research has mostly focused on the evaluation and interpretation of different cost partition methodologies (e.g., Júnior and Hombeeck, 1997; Vieira and Júnior, 1998; Cerqueira and Nebra, 1999; Antunes and Silveira, 1999; Balestieri et al., 1999; Donatelli et al., 2000; Gallo and Gomes, 2003; Júnior and Arriola, 2003), as opposed to the development and application of mathematical exergoeconomic optimization techniques to real, complex thermal systems. To evaluate and compare different exergoeconomic methodologies available in the literature, C. Frangopoulos, G. Tsatsaronis, A. Valero and M. von Spakovsky have proposed the CGAM cogeneration problem (Tsatsaronis, 1994) as a benchmark, which gained wide acceptance thereafter.

Undoubtedly, exergoeconomic evaluation provides insights into system optimization. It allows exergetic costs within a system to be determined, either through the introduction of auxiliary cost equations in cost balance equations, or through the use of functional diagrams and the application of the method of Lagrange multipliers (El-Sayed and Gaggioli, 1989; Gaggioli and ElSayed, 1989). However, to actually perform exact system optimization, the application of a mathematical optimization technique is still required. In general, when a conventional mathematical optimization technique is applied to a thermal system, the thermodynamic balance equations and the component model equations are formulated as restrictions in the optimization problem. Furthermore, these equations must be explicit, and the involved variables must be treated together with the decision variables, thus significantly increasing the dimension of the problem.

Considering that the simulation of real systems requires a large number of thermodynamic variables, it is not surprising that the conventional mathematical optimization of a thermal system is, indeed, a large-scale problem (Jaluria, 1997). For example, even for simulating the relatively simple CGAM cogeneration system, more than 200 variables are required. In fact, due to the complexity of a real problem, the mere application of a conventional optimization procedure is a difficult task, and it may as well be more effective to perform a sensitivity analysis of the system (Frangopoulos, 2003). Ahadi-Oskui et al. (2003) point out that there are only a few well established mathematical optimization techniques available for application to real, complex thermal systems and concluded that large variations in the values of a subset of the decision variables frequently cause little effect on the objective function. Recent reports on the development of optimization tools are given by Egorov et al. (2002) and Knight et al. (2004), respectively for the RDO/IOSO (Robust Design Optimization - Indirect Optimization SelfOrganization) and PSEconomy softwares; however these optimization routines are not available free of charge.

Because both simulation and optimization of complex systems are difficult tasks, it is rational and advantageous, if not strictly necessary, to integrate mathematical optimization algorithms with a professional thermodynamic process simulator. In this manner, not having to deal with the mass, energy, and exergy balance equations, 
the optimization kernel gains significant efficiency. Motivated by the fact that it is not always possible to explicitly obtain the thermodynamic balance equations, and that, in practice, the system to be optimized is already modeled in a process simulator, in this paper the development and implementation of an integrated approach for system optimization is presented and applied to the CGAM cogeneration system.

The proposed approach differs from those applied to the original CGAM problem (Tsatsaronis, 1994). Here, although the same CGAM cogeneration system is considered, the economic, component model and thermodynamic balance equations are not simplified as in the original CGAM problem. Moreover, the conventional mathematical solution of the CGAM problem requires the component model and thermodynamic balance equations to be formulated as restrictions in the optimization problem. Therefore, the mathematical routine is forced to handle not only the decision variables, but also the simulation variables.

The proposed integrated approach has been conceived, in fact, to optimize real complex thermal systems: it fully exploits the computational power of a professional process simulator, and it deals, in the optimization problem, with the decision variables only, while the thermodynamic requirements are completely realized by the simulator. This computationally advantageous strategy, however, might lead to eventual errors in the simulator, due to choices for the values of decision variables in the optimization kernel which would force violation of the laws of thermodynamics. To avoid program crashes in these situations, the objective function is penalized in the optimization kernel, whenever violation of the laws of thermodynamics is observed in the simulator.

In principle, any conventional mathematical optimization algorithm can be implemented in the integrated approach. For computational efficiency, however, a 'derivativefree' method is preferred, because it does not require additional calls to the simulator, to calculate partial derivatives. In this work, the chosen mathematical method is the Flexible Polyhedron Method, developed originally by Nelder and Mead (Himmelblau, 1972). The selected professional process simulator is the IPSE-pro system, version 3 (SimTech, 2000). Because IPSE-pro requires the integration to be performed through the MSExcel, the programming language for computer implementation is the Visual Basic for Applications (VBA). For costing purposes, the straightforward methodology by Lazzaretto and Tsatsaronis (1999), the so-called SPECO/AVCO, is employed. The integrated approach is relatively easy to implement and it can be employed to optimize thermal systems with any degree of complexity, as long as they can be handled by the selected process simulator.

The results obtained for the CGAM system are presented and analyzed, showing the capabilities of the proposed integrated approach. Because the latter does not employ simplified component model and thermodynamic balance equations, the present results cannot be directly compared to those reported by Tsatsaronis (1994) for the CGAM problem.

\section{INTEGRATION WITH THE PROCESS SIMULATOR}

As mentioned, the proposed integrated exergoecomomic optimization technique exploits the power of the IPSE-pro process simulator. As illustrated in Fig. 1, IPSE-pro contains the basic thermal simulator module PSE, which can be coupled with the optional modules MDK (Model Development Kit) and PSE-Excel. In this work, both modules are used, in addition to the Advanced Power Plant Library (APP-Lib), which contains models of thermal systems components. The MDK module permits programming and modification of component models in the APPLib library. With MDK, it is possible to incorporate the exergy property calculation into the simulator. The PSE-Excel module allows integration of the optimization kernel routine with the PSE simulator, through the DDE (Dynamic Data Exchange) protocol. Also, through Excel worksheets, it is possible to exchange variables between the optimization routine and IPSE-pro. Control of data exchange, necessary in the course of the optimization process, is performed using Excel macros, available with PSE-Excel. The optimization routine is written in the VBA language. 


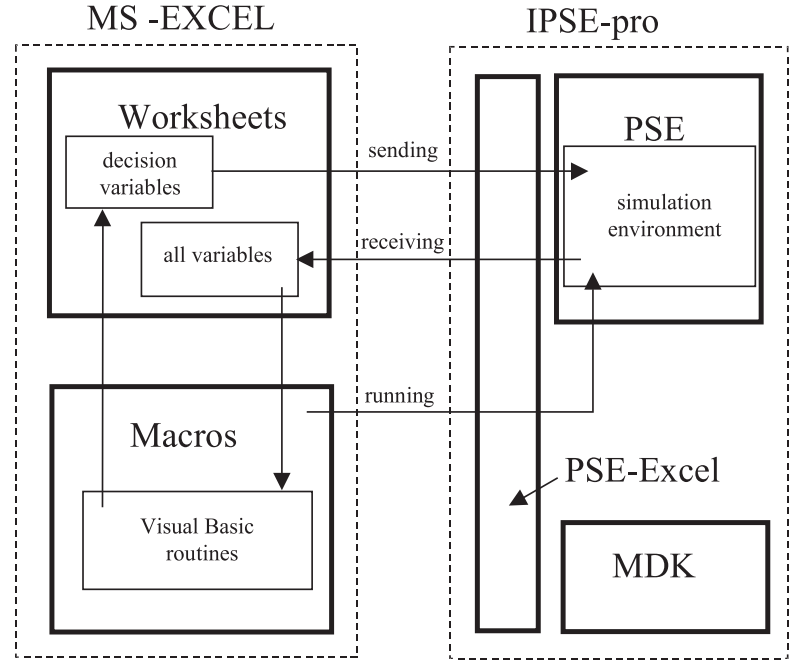

Figure 1. Integration of the optimization procedure with the process simulator

The simulator determines all mass, energy, and exergy flow rates of the system, and it is called by the optimization routine each time a modification of any decision variable is necessary. To prevent failure of the integrated algorithm due to errors caused by selection of unfeasible thermodynamic data in the VBA routine, a penalty value is added to the value of the objective function, whenever IPSE-pro sends an error code to the VBA routine. Note that the optimization routine does not have to deal with the thermodynamic balance equations as restrictions.

The integrated approach allocates great part of the computational effort to the simulator. Total computational time is (roughly) proportional to the number of evaluations by the simulator. In order to reduce calls to the simulator, a direct optimization method - the simple and well-known Flexible Polyhedron Method (Himmelblau, 1972) - has been selected, as opposed to gradient methods that would constantly require additional calls to the simulator, to compute partial derivatives. Here, the method has been adapted to comply with the bounded intervals for the decision variables. First, the definition of an initial polyhedron in the beginning of the iterative process is required. For $\mathrm{n}$ decision variables the polyhedron has $\mathrm{n}+1$ vertices. The first vertex, $\vec{V}_{1}$, of the initial polyhedron,

$$
\vec{V}_{1}=\left\{X_{1}, X_{2}, \ldots, X_{n}\right\}
$$

corresponds to the initial values of the decision variables $X_{i}, i=1, \ldots, n$. Vertex $\vec{V}_{1}$ generates the other vertices $\bar{V}_{2}, \ldots, \bar{V}_{n}, \bar{V}_{n+1}$ according to:

$$
\begin{aligned}
& \vec{V}_{2}=\left\{X_{1}+0.1\left(X_{1, \text { up }}-X_{1, \text { low }}\right) X_{2}, \ldots, X_{n}\right\} \\
& \vec{V}_{n}=\left\{X_{1}, \ldots, X_{n-1}+0.1\left(X_{n-1, \text { up }}-X_{n-1, \text { low }}\right) X_{n}\right\} \\
& \vec{V}_{n+1}=\left\{X_{1}, \ldots, X_{n-1}, X_{n}+0.1\left(X_{n, \text { up }}-X_{n, \text { low }}\right)\right\}
\end{aligned}
$$

\section{APPLICATION TO THE CGAM SYSTEM}

Firstly, the CGAM cogeneration system is described. Secondly, it is shown how the costs are calculated, and how the exergoeconomic analysis of the system is performed. Finally, the optimization problem is formulated and solved. Note that, as explained below, the original CGAM optimization problem is not solved here, because in the proposed approach the economic, component model and thermodynamic balance equations are not similar to the original ones.

\section{The CGAM System}

The CGAM thermal system, shown in Fig. 2, is a cogeneration system that produces fixed amounts of electrical power and saturated steam. The electricity production is $30 \mathrm{MW}$, and the saturated steam mass flow rate at 20 bar is $14 \mathrm{~kg} / \mathrm{s}$. The CGAM system consists of the following five components: air compressor, air preheater, combustor, gas turbine and heat recovery steam generator (HRSG). The combustor fuel is natural gas with a lower heating value of $50000 \mathrm{~kJ} / \mathrm{kg}$.

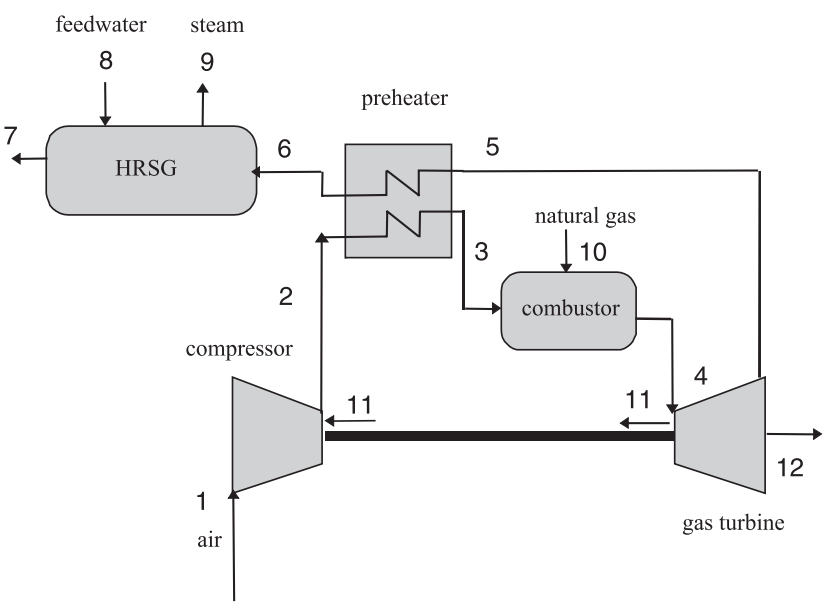

Figure 2. The CGAM cogeneration system 
It is important to stress that, the physical, thermodynamic and economic models used in this paper are different from those of the original CGAM problem (Tsatsaronis, 1994). Here, the physical and thermodynamic models are solved with the IPSE-pro program, not through simplified balance and property equations; and the exergybased economic model consists of component cost equations derived by fitting data points from the original CGAM cost equations.

\section{Cost Equations}

The main costs of a thermal system are the capital investment cost, the operation and maintenance $(\mathrm{O} \& \mathrm{M})$ cost, and the fuel cost. For the purposes of this paper, a simplification of the Revenue Requirement Method (Bejan et al., 1996) is adequate to perform the economic analysis. A simplified economic model is assumed, which is based on the capital recovery factor (CRF), and considers that the total capital investment (TCI) in a plant is given by the sum of all the purchasedequipment costs (PEC) multiplied by a factor $\beta$ (Bejan et al., 1996), as expressed by:

$$
T C I=\sum_{k} T C I_{k}=\sum_{k} \beta P E C_{k}=\beta \sum_{k} P E C_{k}=\beta P E C
$$

where $\mathrm{k}=1, \ldots, \mathrm{NK}$ is the index for the component (or individual equipment) and NK is the total number of components in the plant. The capital recovery factor $(\mathrm{CRF})$ is expressed by:

$$
C R F=\frac{i(1+i)^{\ell}}{(1+i)^{\ell}-1}
$$

where $\ell$ and $i$ are, respectively, the useful system life and interest rate.

The system total cost rate excluding fuel costs, $\dot{Z}$, is the sum of the investment and the O\&M costs for all components, and is given by (Vieira, 2003):

$$
\dot{Z}=\sum_{\kappa=1}^{N K} \dot{Z}_{\kappa}=\frac{\left(\sum_{\kappa=1}^{N K} X P \Phi(1+\gamma) T T X_{\kappa}\right)}{\tau}
$$

where $\tau$ is the yearly plant operating hours and $\gamma$ is the maintenance factor, here assumed constant.

The fuel cost flow rate $\dot{C}_{F}$ is expressed by:

$$
\dot{C}_{F}=c_{F} \dot{m}_{F} L H V
$$

where $c_{F}, \dot{m}_{F}$, and LHV are the specific exergetic cost, mass flow rate, and lower heating value of the fuel (i.e., natural gas), respectively.

The purchased-equipment cost for component $k, \mathrm{PEC}_{\mathrm{k}}$, is expressed in terms of exergy-based quantities, and is given by:

$$
P E C_{k}=B_{k}\left(\frac{\varepsilon_{k}}{1-\varepsilon_{k}}\right)^{n_{k}} \dot{E}_{P, k}^{m_{k}}
$$

where $\varepsilon_{k}$ and $\dot{E}_{p, k}$ are the exergetic efficiency and product exergy flow rate of component $k$, respectively, and $B_{k}, n_{k}$ and $m_{k}$ are fitting parameters.

For the gas turbine and combustion chamber of the CGAM system, however, to correctly evaluate the strong effect of the combustion chamber outlet temperature $T_{4}$ on the component costs, Eq. (9) has been slightly modified to:

$$
P E C_{k}=B_{k} \exp \left(B_{k l} T_{4}+B_{k 2}\left(\frac{\varepsilon_{k}}{1-\varepsilon_{k}}\right)^{n_{k}} \dot{E}_{P, k}^{m_{k}}\right.
$$

In order to obtain all expressions for the purchased-equipment costs, each component $\mathrm{k}$ is individually simulated with the IPSE-pro program, so hat the exergetic efficiency and product exergy flow rate are calculated for many different input operating conditions. With this procedure, aided by efficient nonlinear estimation techniques available with the Statistica 5.0 program (StatSoft, 1996), the values of the $\mathrm{B}_{\mathrm{k}}, \mathrm{B}_{\mathrm{k} 1}, \mathrm{~B}_{\mathrm{k} 2}, \mathrm{n}_{\mathrm{k}}$ and $\mathrm{m}_{\mathrm{k}}$ parameters in Eqs. (9) and (10) for the CGAM system components have been obtained and are shown in Table 1.

Table 1. Values of parameters for purchasedequipment cost equations, Eqs. (9) and (10)

\begin{tabular}{|c|c|c|c|c|c|}
\hline Comp & $\mathrm{B}_{\mathrm{k}}$ & $\mathrm{B}_{\mathrm{k} 1}$ & $\mathrm{~B}_{\mathrm{k} 2}$ & $\mathrm{n}_{\mathrm{K}}$ & $\mathrm{m}_{\mathrm{K}}$ \\
\hline $\mathrm{AC}$ & 51.9 & - & - & 2.50 & 1.002 \\
\hline Comb & 299.9 & 0.014 & -19.90 & 1.04 & 1.002 \\
\hline GT & 181.3 & 0.035 & -53.80 & 1.45 & 1.004 \\
\hline HRSG & 98646 & - & - & 0.78 & 0.649 \\
\hline Pre & 44839 & - & - & 0.92 & 0.371 \\
\hline
\end{tabular}


Finally, the values of the economic parameters used in all the present calculations are: $\beta$ $=2, \quad \ell=10$ years, $\mathrm{i}=12.7 \%, \tau=8000$ hours and $\gamma=0.06$. The adopted value for $\beta$ is realistic, and is based on data available in the literature (Vieira, 2003).

\section{Exergoeconomic Analysis}

An exergoeconomic analysis of the CGAM cogeneration system is performed. Therefore, as detailed in Tsatsaronis (1993, 1994), Bejan et al. (1996) and Vieira (2003), for each component k, $\mathrm{k}=1, \ldots, \mathrm{NK}$, the following quantities must be calculated: exergy destruction flow rate $\left(\dot{E}_{D, k}\right)$, component exergetic efficiency $\left(\varepsilon_{\mathrm{k}}\right)$, exergy destruction and exergetic cost flow rates $\left(\dot{\mathrm{C}}_{\mathrm{D}, \mathrm{k}}\right.$ and $\dot{\mathrm{C}}_{\mathrm{i}}$, respectively), component product and fuel specific exergetic costs $\left(\mathrm{c}_{\mathrm{P}, \mathrm{k}}\right.$ and $\mathrm{c}_{\mathrm{F}, \mathrm{k}}$, respectively), and component investment and O\&M cost flow rate $\left(\dot{\mathrm{Z}}_{\mathrm{k}}\right)$. The fuel and product of each component are calculated as proposed by Lazzaretto and Tsatsaronis (1999). Also, component cost partitioning obeys the rules for fuel and product stated in Lazzaretto and Tsatsaronis (1999). To perform the cost calculations, the incidence, fuel, product and cost matrices are determined following the Theory of the Exergetic Cost (Lozano and Valero, 1993). For the CGAM system, the input specific exergetic cost flow rates are known. The fuel cost is $14.40 \mathrm{US} \$ / \mathrm{MWh}$ whereas the air for combustion and the water for the HRSG are not charged.

\section{The Optimization Problem}

The objective function to be minimized in the optimization problem is the sum of the specific costs of the products (i.e., summation of the plant investment and O\&M costs and the fuel costs). For the CGAM system, specifically, because there is only one fuel and the products are constant, the objective function OF can be given equivalently by:

$$
\begin{aligned}
& O F=\dot{C}_{\text {total }}=\sum_{k=1}^{N K} \dot{Z}_{k}+\dot{C}_{F} \\
& =\frac{\left(\sum_{k=1}^{N K} C R F(1+\gamma) T C I_{k}\right)}{\tau}+c_{F} \dot{m}_{F} L H V
\end{aligned}
$$

As previously mentioned, the process simulator determines all mass, energy and exergy flow rates throughout the system. As opposed to a conventional mathematical optimization procedure, the integrated approach does not require that the thermodynamic balance equations and the component model equations are explicitly written as restrictions of the problem.

For the optimization problem of the CGAM system as described in this section, the chosen decision variables and their limiting values are shown in Table 2 . Note that the decision variables are the same as those of the original CGAM problem (Tsatsaronis, 1994).

Table 2. Decision variables and their limiting values

\begin{tabular}{|c|c|c|}
\hline Variable description & $\begin{array}{c}\text { Variable } \\
\text { symbol }\end{array}$ & $\begin{array}{c}\text { Lower / upper } \\
\text { limit }\end{array}$ \\
\hline compressor pressure ratio & $\mathrm{RPc}$ & $7 / 27$ \\
\hline combustor inlet temperature & $\mathrm{T}_{3}\left({ }^{\circ} \mathrm{C}\right)$ & $427 / 827$ \\
\hline $\begin{array}{c}\text { combustor oulet } \\
\text { temperature }\end{array}$ & $\mathrm{T}_{4}\left({ }^{\circ} \mathrm{C}\right)$ & $827 / 1227$ \\
\hline $\begin{array}{c}\text { compressor isentropic } \\
\text { efficiency }\end{array}$ & $\eta_{\mathrm{AC}}$ & $0.7 / 0.9$ \\
\hline $\begin{array}{c}\text { gas turbine isentropic } \\
\text { efficiency }\end{array}$ & $\eta_{\mathrm{GT}}$ & $0.7 / 0.9$ \\
\hline
\end{tabular}

For the calculations performed in this work, Table 3 displays the initial values of the decision variables and the objective function OF. A case number is assigned to each set of initial values of the decision variables.

Table 3. Initial values of the decision variables and of the objective function $\mathrm{OF}$

\begin{tabular}{|c|c|c|c|c|}
\hline \multirow{2}{*}{$\begin{array}{c}\text { Variable } \\
\text { name }\end{array}$} & \multicolumn{4}{|c|}{ Case } \\
\cline { 2 - 5 } & 1 & 2 & 3 & 4 \\
\hline $\mathrm{RPc}$ & 8.000 & 20.000 & 18.000 & 12.000 \\
\hline $\mathrm{T}_{3}\left({ }^{\circ} \mathrm{C}\right)$ & 626.9 & 525.0 & 500.0 & 500.0 \\
\hline $\mathrm{T}_{4}\left({ }^{\circ} \mathrm{C}\right)$ & 1126.9 & 1225.0 & 1200.0 & 1000.0 \\
\hline$\eta_{\mathrm{AC}}$ & 0.800 & 0.800 & 0.900 & 0.700 \\
\hline$\eta_{\mathrm{GT}}$ & 0.800 & 0.800 & 0.900 & 0.700 \\
\hline $\begin{array}{c}\mathrm{OF}=\dot{\mathrm{C}}_{\text {total }} \\
(\mathrm{USS} / \mathrm{h})\end{array}$ & 1871 & 2133 & 2081 & 13863 \\
\hline
\end{tabular}

\section{RESULTS AND DISCUSSION}

The results are grouped in four cases -1 , $2,3,4$, each corresponding to a distinct set of initial values for the decision variables. As mentioned earlier, the present results cannot be directly compared to those of the original CGAM problem, 
because the economic, physical and thermodynamic models are different; however, as one will note, the results are compatible with those reported by Tsatsaronis (1994).

Figure 3 shows the system total cost rate including fuel costs, as a function of the number of objective function calls (an objective function call is an objective function evaluation which includes a call to the simulator). All curves in Fig. 3 stabilize after enough function calls, and restarting of any of the iterative processes with a new initial polyhedron configuration does not provide additional reduction of the objective function (Vieira, 2003). Also, Table 4 displays: (i) the final values of the decision variables; (ii) the final values of the objective function, $\mathrm{OF}_{\mathrm{f}}$, for each case; (iii) the total number of objective function calls, $\mathrm{N}_{\mathrm{C}}$, for each case; (iv) the individual relative difference $\delta$,

$$
\delta=\frac{\left|O F_{f}-O F_{f b}\right|}{O F_{f b}} \times 100 \%
$$

where $\mathrm{OF}_{\mathrm{fb}}$ is the final value of the objective function for the best case; and (v) the average value $\bar{\mu}$ of the relative differences

$$
\mu_{i}=\frac{\left|X_{i, f}-X_{i, f b}\right|}{X_{i, f b}} \times 100 \%, i=1, \ldots, \mathrm{n}
$$

where $X_{i, f}$ is the final value of decision variable $\mathrm{X}_{\mathrm{i}}$, and $\mathrm{X}_{\mathrm{ifb}}$ is the final value of $\mathrm{X}_{\mathrm{i}}$ for the best case. The best case is Case 4 (Vieira, 2003), the shaded area in Table 4; however, the differences between the $\mathrm{OF}_{\mathrm{f}}$ values for Cases 2, 3 and 4 are negligible.

From Fig. 3 and Table 4, it may be observed that the final value of the objective function for Case 1 is higher than the values for Cases 2, 3 and 4. The largest value of $\delta$ is $0.24 \%$, whereas $\bar{\mu}$ can reach $4 \%$. In fact, individual $\mu_{\mathrm{i}}$ values larger than $14 \%$ are observed, which is an indication of the fact that even the optimization of the CGAM system is not a simple task. As remarked by AhadiOskui et al. (2003), small variations of the objective function can be accompanied by large deviations in the values of some decision variables. In addition to the latter fact, it is observed that the complete simulation of the CGAM cogeneration system requires more than 200 variables. If a conventional mathematical method were applied to optimize the CGAM system, the mathematical routine would have to deal with all the variables. However, with the proposed integrated approach, the optimization routine is allowed to deal with the decision variables only, and it still reaches accurate results. Therefore, the performance of the integrated approach is quite satisfactory.

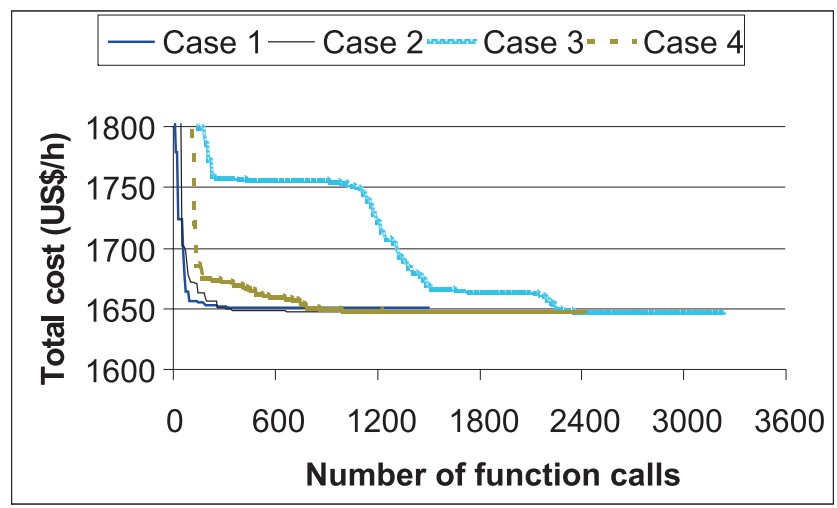

Figure 3. Results of the iterations for Cases 1, 2, 3, 4

Table 4. Final values of the decision variables, OF, $\mathrm{N}_{\mathrm{C}}, \delta$, and $\bar{\mu}$ for Cases $1,2,3,4$

\begin{tabular}{|c|c|c|c|c|}
\hline \multirow{2}{*}{$\begin{array}{c}\text { Variable } \\
\text { name }\end{array}$} & \multicolumn{4}{|c|}{ Cases } \\
\cline { 2 - 5 } & 1 & 2 & 3 & 4 \\
\hline $\mathrm{RPc}$ & 7.000 & 8.195 & 8.201 & 8.201 \\
\hline $\mathrm{T}_{3}\left({ }^{\circ} \mathrm{C}\right)$ & 634.4 & 608.0 & 607.7 & 609.0 \\
\hline $\mathrm{T}_{4}\left({ }^{\circ} \mathrm{C}\right)$ & 1227.0 & 1227.0 & 1227.0 & 1227.0 \\
\hline$\eta_{\mathrm{AC}}$ & 0.869 & 0.873 & 0.873 & 0.873 \\
\hline$\eta_{\mathrm{GT}}$ & 0.842 & 0.837 & 0.837 & 0.838 \\
\hline $\mathrm{OF}_{\mathrm{f}}(\mathrm{US} \$ / \mathrm{h})$ & 1651 & 1647 & 1647 & 1647 \\
\hline $\mathrm{N}_{\mathrm{C}}$ & 1509 & 1414 & 3235 & 2414 \\
\hline$\delta(\%)$ & 0.24 & 0.00 & 0.00 & 0.00 \\
\hline $\bar{\mu}(\%)$ & 3.97 & 0.06 & 0.06 & 0.00 \\
\hline
\end{tabular}

A comparison between the limiting values and the final values of the decision variables, respectively shown in Tables 2 and 4, reveals that the minimum of the objective function does not correspond to the largest values of the compressor and turbine efficiencies. Indeed, minimization of the objective function requires the correct balance between exergy destruction and investment costs. To aid interpretation of the results from an exergoeconomic point of view, the initial and final system global costs are presented in Table 5, together with the ratio of the exergy destruction cost to the investment cost. For the CGAM system, the final value of this ratio is seen to fall between 1.77 and 1.87. Consistently for all cases, a final 
exergy destruction cost lower than the initial one is attained. Also, only for Cases 1 and 2 the final investment costs are higher at the optimum than in the beginning of the iterations.

Table 5. Initial and final system global costs

\begin{tabular}{|c|c|c|c|c|c|}
\hline \multirow{2}{*}{\multicolumn{2}{|c|}{ Case }} & \multicolumn{2}{|c|}{ System Cost (US\$/h) } & \multirow{2}{*}{$\begin{array}{c}\text { Exergy } \\
\text { Destruct./ } \\
\text { Invest. }\end{array}$} & \multirow{2}{*}{$\begin{array}{c}\mathrm{OF} \\
(\mathrm{US} \$ / \mathrm{h})\end{array}$} \\
\hline & & Invest. & $\begin{array}{c}\text { Exergy } \\
\text { Destruct. }\end{array}$ & & \\
\hline \multirow{2}{*}{1} & initial & 483 & 993 & 2.06 & 1871 \\
\hline & final & 508 & 949 & 1.87 & 1651 \\
\hline \multirow{2}{*}{2} & initial & 423 & 940 & 2.22 & 2133 \\
\hline & final & 507 & 901 & 1.78 & 1647 \\
\hline \multirow{2}{*}{3} & initial & 1010 & 909 & 0.90 & 2081 \\
\hline & final & 507 & 900 & 1.78 & 1647 \\
\hline \multirow{2}{*}{4} & initial & 1096 & 5625 & 5.13 & 13863 \\
\hline & final & 509 & 899 & 1.77 & 1647 \\
\hline
\end{tabular}

The integration of the flexible polyhedron mathematical method developed by Nelder and Mead (Himmelblau, 1972) with the IPSE-pro process simulator (SimTech, 2000) allows the optimization routine to handle just the decision variables, saving time in the optimization kernel. Because the number of variables dealt with by the optimization routine is relatively small (5) with respect to the number of variables required for system simulation (over 200), the total CPU time for executing the iterative optimization process depends mainly on the time demanded by the simulator, which scales with the number of simulation variables. For the CGAM cogeneration system, the average CPU time for complete optimization is 48.7 minutes on a Pentium II 850 $\mathrm{MHz} / 256 \mathrm{Mb}$ RAM computer. To obtain objective function values $5 \%$ higher than the minimum value, only 7.7 minutes are required.

\section{CONCLUSIONS}

Thermodynamic simulation programs are widely used for designing complex thermal systems, but most of them do not incorporate second law optimization techniques. In this study, an efficient optimization strategy is presented, which integrates a well-known and simple mathematical optimization algorithm with a professional process simulator, so as to be able to perform exergoeconomic optimization of complex thermal systems. The selected mathematical algorithm is the flexible polyhedron method, and the process simulator is the IPSE-pro system. All costs are calculated on an exergy basis. The proposed approach is applied to the CGAM cogeneration system.

A conventional mathematical optimization approach applied to the cogeneration system treated in this work, but not using a simulator and adopting simplified mass, energy and entropy balances as restrictions in the optimization problem, would require the manipulation of $\mathrm{O}\left(10^{2}\right)$ variables. Integration of the mathematical method with the simulator permits a reduction in the number of variables dealt with by the optimization routine by two orders of magnitude.

The proposed integrated approach has proved effective: the coupling of the mathematical algorithm to the simulator does lead to the optimization of the CGAM thermal system. Discrepancies in the final values of the objective function corresponding to different initial points are below the small margin of $0.25 \%$. These results highlight the potential of the proposed integrated approach to handle real complex thermal systems, with the optimization routine having to deal only with the decision variables (Vieira, 2003).

Finally, it has been observed that the objective function is not sensitive to some decision variables near the optimum. In view of this fact, as an efficient alternative to the optimization process, we suggest that an improvement procedure should be applied, based also on exergoeconomics, such that only the decision variables that significantly affect the objective function are considered (Vieira, 2003; Vieira et al., 2003; Vieira et al., 2004).

\section{ACKNOWLEDGEMENTS}

Manuel Ernani Cruz would like to gratefully acknowledge the financial support of CNPq (Grant 500086/2003-6, former 521002/974 ) and FAPERJ (Grant Cientistas do Nosso Estado E-26/151.961/ 2004).

\section{REFERENCES}

Ahadi-Oskui, T., Cziesla, F., Tsatsaronis, G., Alperin, H., and Nowak, I., 2003, RelaxationBased Heuristics for the Design of Cost-Effective Energy Conversion Systems, In: 16th Conference on Efficiency, Cost, Optimization, Simulation and Environmental Impacts of Energy Systems - ECOS, Copenhagen, Denmark. 
Antunes, J. S., and Silveira, J. L., 1999, Cogeração em Ciclos Combinados: Um Programa Computacional para Análise Exergoeconômica, In 15th Brazilian Congress of Mechanical Engineering - COBEM, Águas de Lindóia, SP, Brazil. (in Portuguese)

Balestieri, J. A. P., Nogueira, L. A. H., Nebra, S. A., Júnior, S. O., and Gallo, W. L. R., 1999, Metodologias para Análise de Sistemas Energéticos - Mesa Redonda, Simpósio 1: Análise de Sistemas Energéticos, In: 15th Brazilian Congress of Mechanical Engineering - COBEM 1999, Águas de Lindóia, SP, Brazil. (in Portuguese)

Bejan, A., Tsatsaronis, G., and Moran, M., 1996, Thermal Design and Optimization, John Wiley \& Sons, Inc., New York.

Cerqueira, S. A. G., and Nebra, S. A., 1999, Cost Attribution Methodologies in Cogeneration Systems, Energy Conversion and Management, Vol. 40, pp. 1587-1597.

Donatelli, J. L. M., Vieira, L. S. R., and Cruz, M. E. C., 2000, Avaliação Exergoeconômica Comparativa de Acionadores Primários de Plantas de Cogeração, In: VIII Congresso Brasileiro de Engenharia e Ciências Térmicas - ENCIT, Porto Alegre, RS, Brazil, pp. 1-10. (in Portuguese)

Donatelli, J. L. M., 2002, Otimização Estrutural e Paramétrica de Sistemas de Cogeração Utilizando Superestruturas, Doctoral Thesis, COPPE/Federal University of Rio de Janeiro, Rio de Janeiro, RJ, Brazil. (in Portuguese)

Egorov, I. N., Kretinin, G. V., and Leshchenko, I. A., 2002, Robust Design Optimization Strategy of IOSO Technology, In: H. B. Orlande (ed.), Inverse Problems in Engineering, Theory and Practice, Vol. I, E-Papers Publishing House, Ltd., Rio de Janeiro, RJ, Brazil.

El-Sayed, Y. M., and Gaggioli, R. A., 1989, A Critical Review of Second Law Costing Methods - I: Background and Algebraic Procedures, ASME Journal of Energy Resources Technology, Vol. 111, pp. 1-7.

Frangopoulos, C. A., 2003, Methods of Energy Optimization, OPTI Energy Summer School, Gliwice, Poland.

Gaggioli, R. A., and El-Sayed, Y. M., 1989, A Critical Review of Second Law Costing Methods - II: Calculus Procedures, ASME Journal of Energy Resources Technology, Vol. 111, pp. 8-15.

Gallo, W. L. R., and Gomes, C. M., 2003, Exergoeconomic Analysis of a Combined Cycle with Industrial Cogeneration, In: 16th Conference on Efficiency, Cost, Optimization, Simulation and Environmental Impacts of Energy Systems - ECOS, Copenhagen, Denmark.

Himmelblau, D. M., 1972, Applied Nonlinear Programming, McGraw-Hill, New York. Jaluria, Y., 1997, Design and Optimization of Thermal Systems, McGraw-Hill, New York.

Júnior, S. O., and Arriola, D. W. G., 2003, Tetra-combined Trigeneration System Energy and Thermoeconomic Analysis, In: 16th Conference on Efficiency, Cost, Optimization, Simulation and Environmental Impacts of Energy Systems - ECOS, Copenhagen, Denmark.

Júnior, S. O., and Hombeeck, M. V., 1997, Exergy Analysis of Petroleum Separation Processes in Offshore Platforms, Energy Conversion and Management, Vol. 38, pp. 1577-1584.

Knight, R., Linder, U., Markworth, N., and Perz, E., 2004, Thermo-economic Optimization of whole Gas Turbine Plant (GTPOM), Applied Thermal Engineering, Vol. 24, pp. 1725-1733.

Lazzaretto, A., and Tsatsaronis, G., 1999, On the Calculation of Efficiencies and Costs in Thermal Systems, In: S. M. Aceves et al. (eds.), ASME Advanced Energy Systems Division, AESVol. 39, ASME, New York.

Lozano, M. A., and Valero, A., 1993, Theory of the Exergetic Cost, Energy, The International Journal, Vol. 18, No. 9, pp. 939-960.

Rosen, M. A., and Dincer, I., 2001, Exergy as the Confluence of Energy, Environment and Sustainable Development, Exergy - an International Journal, Vol. 1, No. 1, pp. 3-13.

Rosen, M. A., and Dincer, I., 2003, ExergyCost-Energy-Mass Analysis of Thermal Systems and Processes, Energy Conversion and Management, Vol. 44, pp. 1633-1651.

SimTech, 2000, IPSE-pro User Documentation - Version 3.1, Austria.

StatSoft, Inc., 1996, STATISTICA for Windows Computer Program Manual, Tulsa, OK.

Tsatsaronis, G., 1993, Thermoeconomic Analysis and Optimization of Energy Systems, Progress in Energy and Combustion Science, Vol. 19, No. 3, pp. 227-257.

Tsatsaronis, G. (guest editor), 1994, Special Issue, Invited Papers on Exergoeconomics, Energy, The International Journal, Vol. 19, No. 3, pp. 279-381.

Vieira, L. S. R., 2003, Modelo Exergo- 
econômico Iterativo para Melhoria de Sistemas Térmicos Complexos Integrado a um Simulador de Processos Profissional, Doctoral Thesis, COPPE/Federal University of Rio de Janeiro, Rio de Janeiro, RJ, Brazil. (in Portuguese)

Vieira, L. S. R., Donatelli, J. L. M., and Cruz, M. E. C., 2003, Iterative Exergoeconomic Improvement of a Model Cogeneration System with the Aid of a Process Simulator, In: First International Exergy, Energy and Environment Symposium, pp. 259-265, Izmir, Turkey.

Vieira, L. S. R., Donatelli, J. L. M., and Cruz, M. E. C., 2004, Integration of an Iterative Methodology for Exergoeconomic Improvement of Thermal Systems with a Process Simulator, Energy Conversion and Management, Vol. 45, No. 15-16, pp. 2495-2523.

Vieira, S., and Júnior, S. O., 1998, Estudo de Sistemas de Cogeração Termelétrica através da Análise Termoeconômica, in: Anais do VII Congresso Brasileiro de Engenharia e Ciências Térmicas - ENCIT, Rio de Janeiro, RJ, Brazil, pp. 381-386. (in Portuguese) 